Session 2213

\title{
Construction and Testing of a Pilot Scale Drinking Water Treatment Process
}

\author{
Paul D. Dunbar*, Lori Morris ${ }^{+}$, and L. Yu Lin ${ }^{++}$ \\ *Department of Chemical Engineering, University of Kentucky, Paducah Extension Campus, \\ Paducah, $\mathrm{KY} /{ }^{+}$Ensafe Inc., Memphis, $\mathrm{TN} /{ }^{++}$Christian Brothers University, Department of Civil \\ Engineering, Memphis, TN
}

\begin{abstract}
This project was a senior design project for a civil engineering student. The project's goal was to build a cost-effective and energy efficient system to treat surface water on a pilot scale. Due to its relatively inexpensive costs and the safe nature of the project, this type of project can serve as an open-ended design and economic study for a group of students, which they can build what they design. This system would serve as a lab experiment and a continued senior project to improve its removal efficiency. A multi-discipline team could fit various measurement devices such as $\mathrm{pH}$ and turbidity and design a feedback control scheme to optimize the water treatment process. This paper demonstrates that such a system is feasible, and it can serve as a great learning experience for a relatively small cost. The student and an adjunct faculty member designed and constructed this system at Christian Brothers University in Memphis, TN with the help of another student and a volunteer retiree with industrial experience. The base system was designed to treat water collected from the Mississippi River at a $4.5 \mathrm{gpm}$ flowrate at a capital cost of approximately $\$ 2300$. This system effectively treated water pumped from the Mississippi River and met drinking water standards that it was designed for. The system consisted of an equalization basin tank, feed pump, dosing pump with chemical reservoir, a static mixer, settling tank, and a three-layer filter. The system was portable and powered by a portable generator A truck transported the system to the river. The system design was based on the addition of organic polymer/inorganic coagulants added to the feed stream. The use of stateof-the art polymers greatly reduced the system's size. This paper presents the system design and operating limitations. An improved design is also presented costing less than $\$ 9,000$. The alternative system consists of items purchased from vendors and could be assembled by students. This system is intended to be for education and demonstration. The senior student considered this project to be her best educational experience in college. This type of project greatly improves a student's design and critical thinking skills.
\end{abstract}

Introduction This project was intended to be a senior project and to serve as a laboratory experiment for civil/environmental and chemical departments. Initially the project's goal was to design and built a solar powered water treatment system, but building an effective energy efficient mixing process in the flocculation tank posed a problem not easily solved at that time. The solar energy panel costs for powering the mixers were quite high and the construction of the baffled flocculator was quite tedious. As a result, a more traditional system was designed to be powered by a gasoline fueled generator. The generator powered pumps and gear motors to facilitate the conversion of river water to drinking water. The system was designed for portability using a flat bed truck or a truck with a 12-foot long trailer. The system was transported to the Mississippi river to demonstrate how surface water could be treated. The 
equalization basin and main flocculation/sedimentation/filter tank was built on casters for mobility. Also, 4" x 4" lumber was used as a support so that a forklift could be used to load it if necessary. Due to a lack of funds it was desired to be inexpensive yet able to meet acceptable drinking water quality standards. The system was designed based on water collected from the Mississippi River at a location in Shelby Forest State Park, North of the City of Memphis. Lab tests determined the proper coagulant dosing and sediment settling time. The Mississippi river supplies drinking water for several cities in the United States including the City of New Orleans and St. Louis, MO.

\section{Background Information}

In Typical surface water treatment systems, there are 5 processes that are used to treat surface water. These processes include:

- $\quad$ Coagulant Addition and Mixing

- Flocculation

- Sedimentation

- Filtration

- Disinfection

Figure 1 shows the typical treatment train for surface water. Surface water flows into the system and it is mixed with a coagulant. After mixing, the water flows into the flocculation basin where it is gently mixed to facilitate the coalescence of the colloidal particles into large particles. The water flows into a sedimentation basin where the large particles drop to the bottom of the tank forming a layer of sludge. Sludge consists of various particles and microorganism suspended in the surface water. It is necessary to remove the sludge from the clarifier. Water overflows from the surface of the clarifier into the filter via the weir. The turbidity is further reduced as particles and organisms migrate from the water to the filter media's surface due to mass transport gradients. Fiinally, a disinfectant is added to destroy microorganisms.

\section{Figure 1- Typical Treatment train for Surface Water}

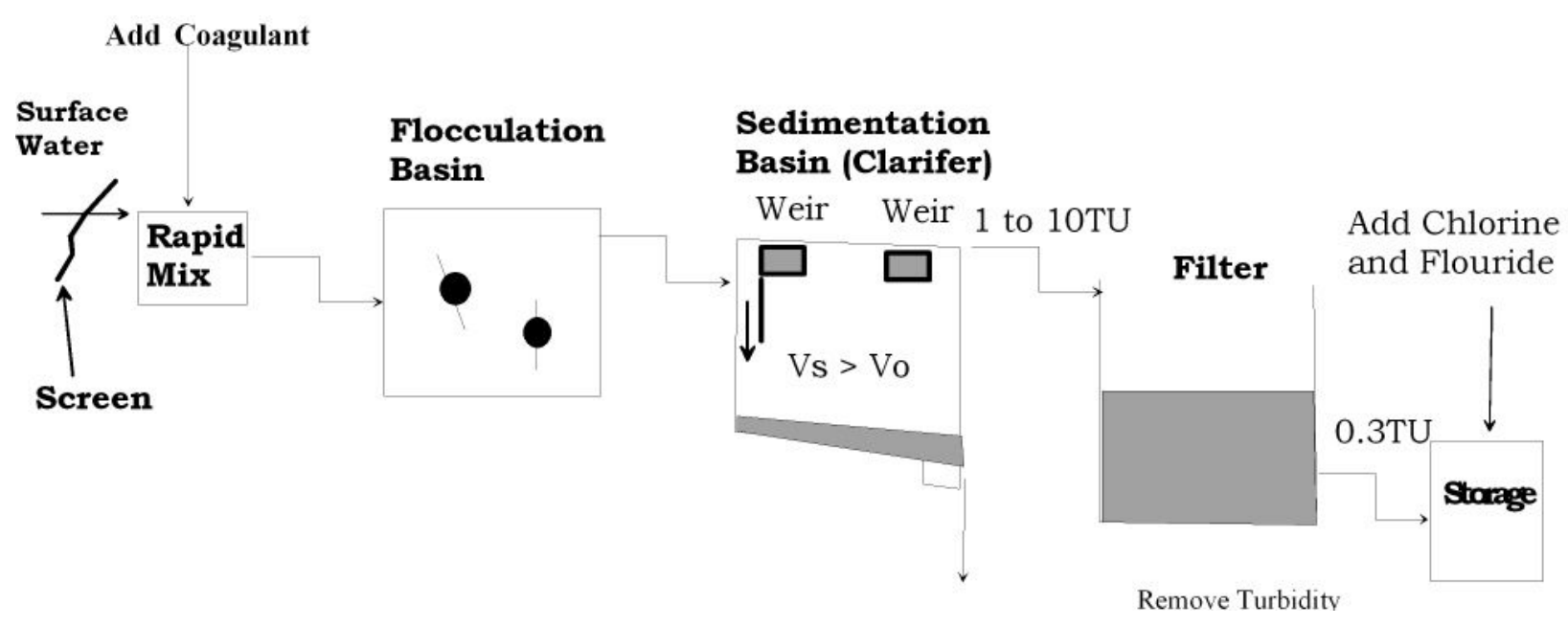

\section{Alternative Treatments}

This system consists of technologies commonly found in surface water treatment systems. However, newer technologies could be utilized if determined to be economically viable or the 
water quality constraints require them. State-of-the-art surface water purification includes several other techniques including reverse osmosis, membrane filtration, cartridge filtration, ion exchange, electrodialysis, aeration, and softening. On the other hands, students could attempt to build a solar powered treatment system. Such a project would certainly produce student enthusiasm. It should be noted that many universities incorporate newer surface water treatment technologies into their laboratory experiments. This paper does not exclude these technologies as an alternative to water treatment.

\section{Experimental System}

Figure 2 shows the system that was designed and built for this project. It consists of two pumps, an equalization basin, static mixer, flocculation tank, sedimentation tank, and a filter. The system's rough dimensions are 4 feet high, 8 feet long, and 4 feet wide. The equalization basin is not shown.

\section{Figure 2 System Designed and Constructed System Design and Construction}

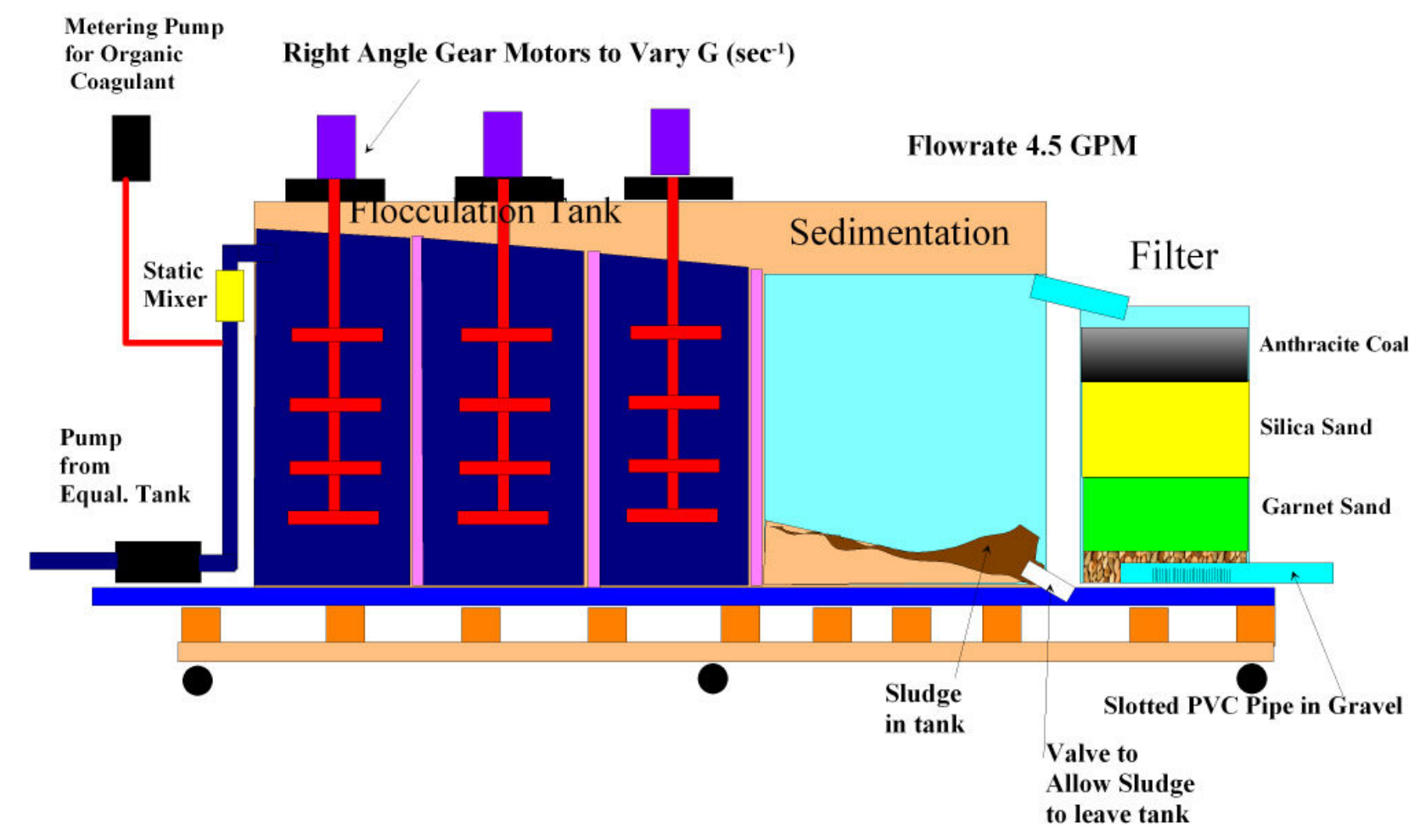

In general, the system was designed based on a flowrate of $4.5 \mathrm{gpm}$, and the use of a highly efficient organic polymer to cause rapid particle coalescence in the flocculator and settling in the clarifier.

\section{Pumps}

A pump with a capacity of $20 \mathrm{gpm}$ at 50 feet of head was leased to collect water from the river and deliver it to the equalization basin. This pump was operated intermittently. The leasing fee was $\$ 20$ a day. A small centrifugal pump manufactured by March Model DX-3 centrifugal 
pump (\$110.00) was used to remove the water from the equalization tank to the flocculation tank. This pump had a rating of $6 \mathrm{gpm}$ at 0 feet of head. This pump had virtually no suction head. As a result, a water level above the pump intake was necessary for the pump to work properly. The pump's power rating is quite low, only $1 / 55^{\text {th }}$ of a horsepower. This was the most economical choice for a pump to perform this job. A small feed pump delivered the proper dosage of (LMI Roy Solenoid Diaphragm Pump Model number 74502-00) coagulant to the system.

\section{Mixer}

A static mixer was used to perform the mixing having an ID of 1.029 inches, and a length of 11 inches. It became apparent that a static mixer was insufficient and an in-line motorized mixer is necessary to properly mix the coagulant with the inlet feed stream into the system.

\section{Coagulant}

The type and quantity of coagulants are determined by using a jar test. Coagulants can be classified as inorganic and organic. Typically inorganic coagulants depress the $\mathrm{pH}$ of the system and lime is added to raise the $\mathrm{pH}$ back to acceptable levels. Using a polymer can eliminate the need for this step. The coagulant that was used for this design is an aluminum chloride/organic polymer mixture developed by the Nalco Chemical Company in Napierville, IL. Based on a jar test, the required dosage is $60 \mathrm{ppm}$ for the proper flocculation to occur. For this setup it was determined that 1 part coagulant should be diluted with 19 parts distilled water. This allows the coagulant to easily flow (low viscosity) in tubing with a low-pressure drop.

\section{Flocculation}

Flocculation is the process that brings the colloid particles together so they can settle in the clarifier. The mixing must be very precise: an inadequate amount of mixing energy will cause settling in the flocculation basin; too much energy will cause the floc particles to break (Davis, 1998). As the water moves through the basin, the velocity gradient (G) should decrease to prevent the flocs from breaking. Equation 1 describes the velocity gradient. $G$ is a function of volumetric flowrate $(Q)$, headloss in the flocculator $(\Delta H)$, water's density $(\rho)$, viscosity $(\mu)$, and volume of the tank $(\mathrm{V})$. In this system a variable speed motor/gear reducer drives a shaft fitted with wooden paddles cut to the proper size to deliver a range of velocity gradients in the flocculation tank.

$$
\text { (1) } G=\sqrt{\left(\frac{Q \rho g \Delta H}{\mu V}\right)}
$$

The flocculation tank is divided into 3 compartments partially separated by Plexi-glass sheeting allow velocity gradient variations. Each compartment has its own individual gear motor/controller.

The gear motors are 1/15 hp Dayton AC gear motors (Grainger Part No. 2Z802, \$149.55 each) each controlled by the AC Motor Speed Controllers (Grainger Part No. 4X796, \$26.65 each), which can lower the speed to between 30 and 45 rpms. The tank is 2 feet wide, 3 feet deep, with 3 compartments each a foot long. The paddle designs were devised according to 
parameters found in Unit Operations and Processes in Environmental Engineering by Reynolds (1996).

For this design of the horizontal paddle flocculator, each compartment's paddle set must operate at different rotational speeds to control the $G$ value needed to form the flocs (Reynolds, 1996).

\section{Sedimentation}

During the Sedimentation process, the flocs that were formed in the coagulation and flocculation tank are now ready to settle. To design the sedimentation process, first a detention time must be determined. After the experimental jar test, the flocs were allowed to settle and after a period of approximately 30 minutes, a majority of the flocs had settled. The sedimentation basin has a volume of 135 gallons or $18.05 \mathrm{ft}^{3}$. This value is based on using the design flowrate $\mathrm{Q}=4.5 \mathrm{gals} / \mathrm{min}$ and a detention time of 30 minutes. This design will have a $3 \mathrm{ft}$ depth, $2.5 \mathrm{ft}$ width, and $2.5 \mathrm{ft}$ length. These dimensions are crucial for the sediment process. The particle must have a large enough distance to travel laterally as well as in the vertical direction. If the lateral distance is too short, the particle will possibly be released through the weir instead of settling. If the vertical direction is too short or too long, the particle will not settle properly and can be released through the weir.

\section{Figure 3. Flocculation Basin Paddle Design with Motor, Coupling, \& Shaft}

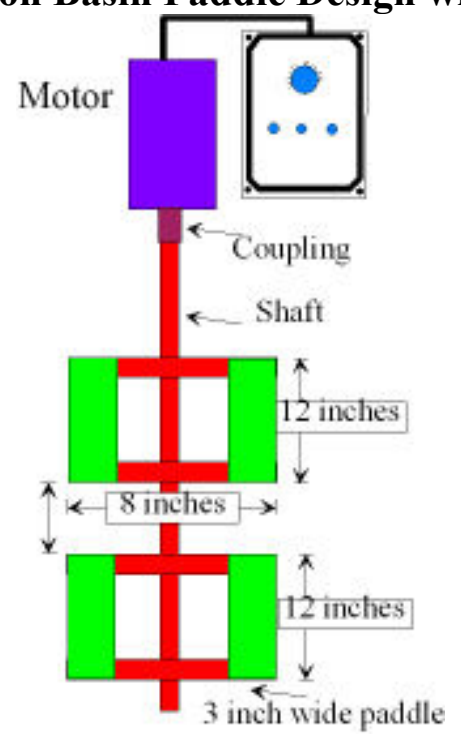

The weir design for the system is simply a spill over area of $24 \times 4$ inches. For the flowrate into the filtration process, the weir is long enough to provide the flowrate needed into the filter so to prevent back flow into the system.

\section{Filtration}

When designing a filter, factors such as detention time and adequate media are crucial in providing the appropriate percent removal. In general, the common range of flowrate through the rapid sand filter is 1 to $10 \mathrm{gal} / \mathrm{ft}^{2}-\mathrm{min}$. For this system, the flowrate entering the filter is 4.5 $\mathrm{gal} / \mathrm{min}$. The area of the filter was $3 \mathrm{ft}^{2}$. This resulted in a flow of $1.5 \mathrm{gal} / \mathrm{ft}^{2}-\mathrm{min}$.

\section{Construction Details}


Figure 4 shows a side view of the Equalization basin construction plans. It is constructed of plywood lined with acrylic sheeting sealed with water proof epoxy, 2x4's, 4x4's, and steel bolts. The tank's volume is a cubic yard or about 200 gallons. After a few layers of epoxy and caulk, the tank sealed up and did not leak. Figure 5 shows the flocculation/sediment tank which was made of similar construction materials. Due to the need of sloping floors, it was more difficult to construct and despite multiple layers of epoxy and caulk- the tank would not completely seal up and some leakage occurred. Figure 6 shows the entry to the filter construction. A layer of plexy glass was added to the top of the filter and holes were drilled to allow an even distribution of water across the filter. The filter consists of three layers of anthracite coal, silica sand, and granite sand over a layer of gravel and slotted PVC pipe that channels the water out of the system. Samples were collected at this exit point. There was no disinfection step in this system due to budget constraints. The completed system is shown in Figure 7. This figure shows the generator, equalization basin, floc/settling tank and filter. The dosing pump and coagulant reservoir can be seen on top of the equalization basin. The system is sitting in a parking lot above the Mississippi River in Meeman-Shelby Forest State Park just north of the City of Memphis. A bobcat with forklift attachment was used to move the system from the truck to the parking lot surface. One oversight was not asking permission from the Tennessee State Park to perform this experiment at this location. However, the Park Ranger found the experiment to quite interesting and allowed it to proceed. A significant crowd gathered and asked questions concerning the activity.

\section{Figure 4. Side View of Equalization Basin}

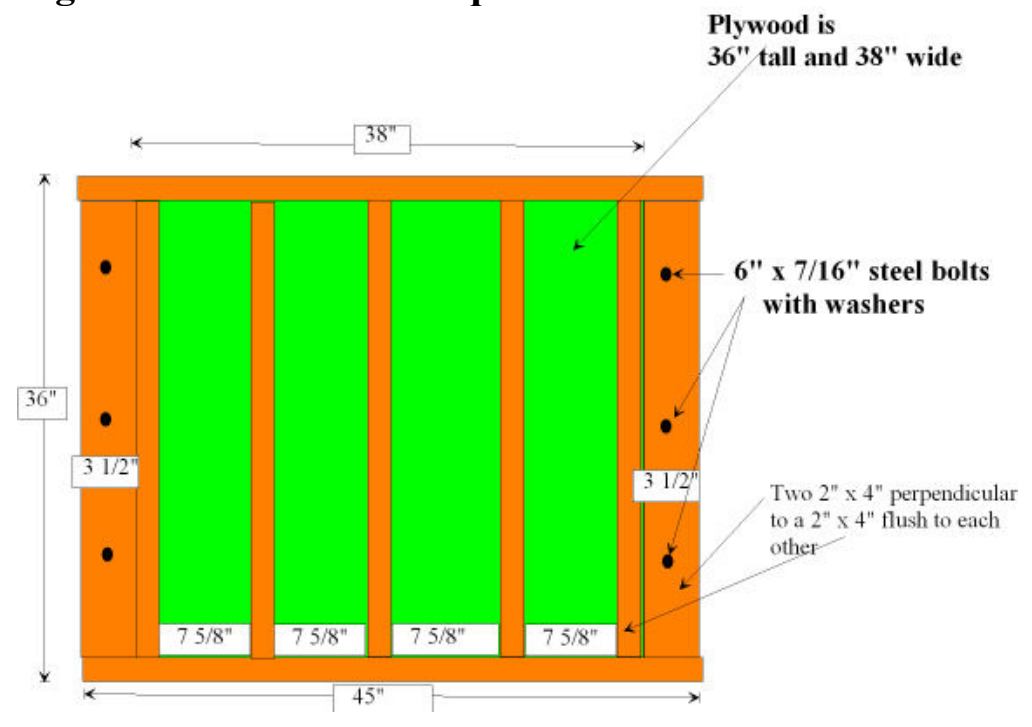


Figure 5 Top View of Flocculator and Settling Basin

3/4" Plywood 24"wide x 36" high

Short Side

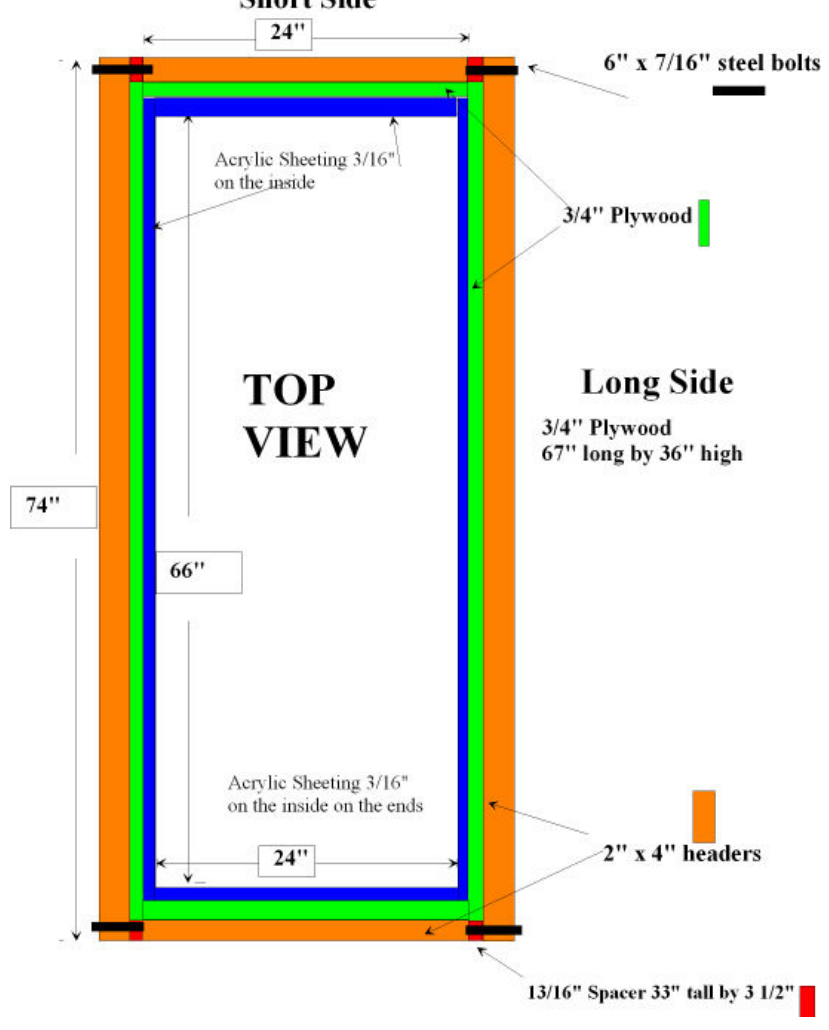

Figure 6 Top view of Filter with perforated Acrylic sheeting to spread flow evenly across the filter

$$
\text { Top View }
$$

Plate covering The Filter to distribute water evenly
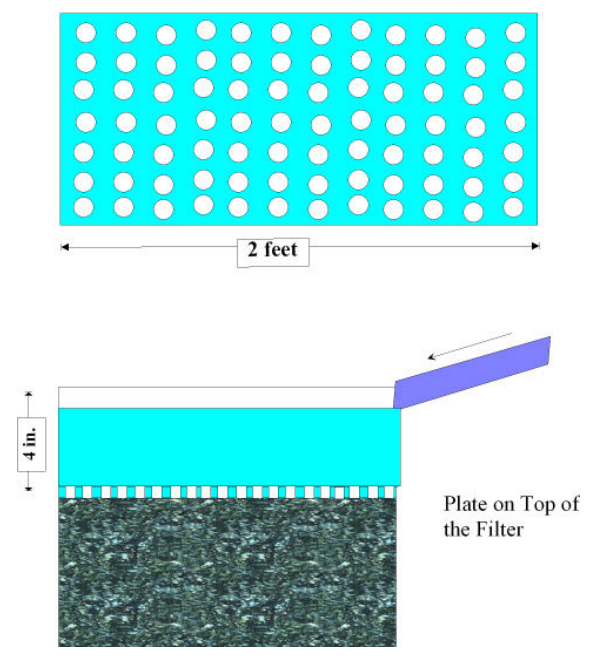

Proceeding of the 2004 American Society for Engineering Education Annual Conferences \& Exposition 


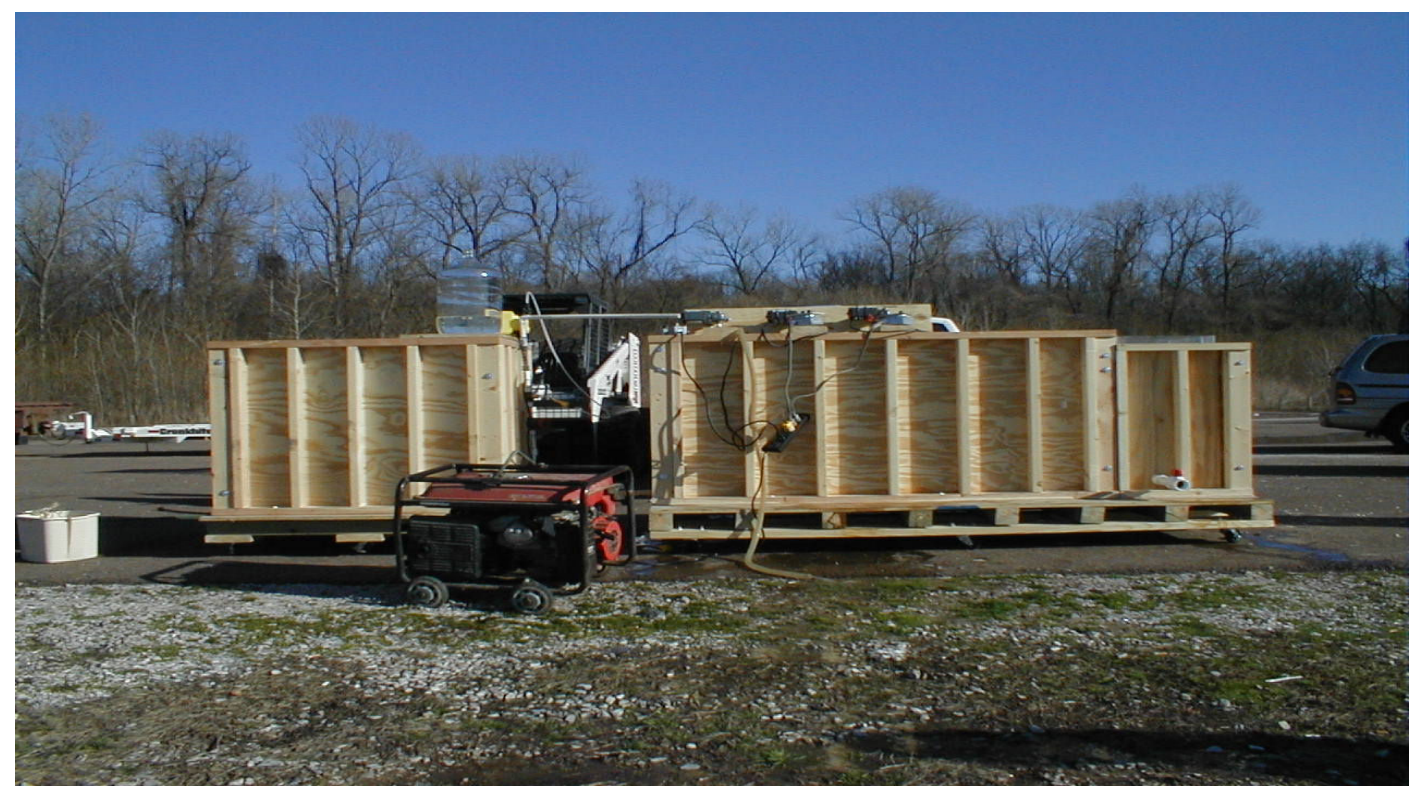

\section{Results and Analysis}

The system treated water from the Mississippi River water in March of 2000. The water was tested by Memphis Light Gas \& Water for VOCs, metals, $\mathrm{pH}$, turbidity, etc. The results are given in Table 1.

Table 1. Test Results from Mississippi River Water

\begin{tabular}{llll} 
Parameter & Before & After & Standard* $^{*}$ \\
\hline Turbidity & 32 & 0.15 & $<1.0$ \\
nitrate & $2.09 \mathrm{mg} / 1$ & $\mathrm{ND}$ & $10 \mathrm{mg} / 1$ \\
Chloride & $10 \mathrm{mg} / 1$ & $5 \mathrm{mg} / \mathrm{l}$ & $250 \mathrm{mg} / 1$ \\
Iron & $0.14 \mathrm{mg} / 1$ & $0.01 \mathrm{mg} / 1$ & $<0.05$ \\
Hardness & $183 \mathrm{mg} / 1$ & $145 \mathrm{mg} / 1$ & $<80.0$ \\
$\mathrm{pH}$ & 5.65 & 6.05 & 6.5 to 8.5 \\
Bacterial & Fecal & Reduction & \\
Count & Coliforms & & \\
\hline
\end{tabular}

* Standards based on Secondary Maximum Limits and American Water Works Association (Cornwall)

The system greatly reduced the turbidity and iron to drinking water standards. Nitrate and chloride were already below drinking water standards. The $\mathrm{pH}$ was not depressed by the coagulants, but it was desirable to raise the $\mathrm{pH}$ to at least 6.5. The fecal coliform count was reduced by the system, but it is unknown by how much since MLG\&W did not do the proper bacterial dilutions. MLG\&W usually analyzes groundwater which has a very low bacterial count and they do not work with surface water. A disinfection process would be necessary for acceptable biological standards for drinking water.

The hardness of the water was quite high for surface water, and it does not meet the standards. This was not expected for surface water, since surface water is typically rated as soft 
and groundwater is usually hard. While the system was running, it was observed that the settling process was inadequate possibly due to the incorrect coagulant dosage and residence time. The system design calculations were based on water tested in the fall. The water temperature at that time was warmer than the water used in March. This is one possible explanation why the system did not perform as well as expected. The most likely explanation for this lack of settling performance is that the six-inch static mixer did not adequately mix the coagulant with the river water. In the laboratory tests, the coagulant was mixed for a longer time. Additional static mixers could be added to improve the mixing to increase the mixing residence time, or an in-line impeller mixer with a volume of 4.5 gallons should be substituted for the static mixer. This would result in a residence time of 1 minute for the rapid mixing of the coagulant. Essentially the filter removed the turbidity and other constituents from the water. The filter's life is greatly decreased without proper settling in the system.

Leaks were a problem in the construction of the system. There was difficulty in eliminating leaks in the system. In the final tests, all leaks were eliminated except from the filter. To solve this problem requires further work. It was difficult to seal up seams between the acrylic sheeting even with the proper acrylic to acrylic cement. Silicon caulk was used extensively in the building process.

\section{System Cost}

Table lists materials and their costs. The cost for the acrylic sheeting is shown in the table, but in reality, The Dupont Corporation donated it. Nalco Chemical Inc donated the coagulant. The lumber was purchased from Home Depot.

Table 2: System Cost Traditional Design

\begin{tabular}{lr}
\hline \hline Static Mixer & 90.00 \\
Piping & 30.00 \\
Feed and Metering Pump & 343.00 \\
Coagulant for one day & .70 \\
Lumber & 400.00 \\
Acrylic (14 sheets@50ea.) & 700.00 \\
AC Gear Motors/Controllers & 576.00 \\
Paddles & 5.00 \\
Filter Media & 87.00 \\
Wheels \& flange bearings & 101.00 \\
& \\
\hline \hline Total & $\$ 2352.70$ \\
\hline \hline
\end{tabular}

\section{Improved System Design}

An alternative system design would consist of pre-fabricated plastic tanks purchased from vendors. A table below presents prices from catalogs and from verbal quotes using the approximately same volumes, heights, and widths of the system constructed. This would eliminate leaks and it also includes an ozonator for disinfection. Alternative less expensive methods could be used as well such as adding some doses of bleach and the aerating to remove any excess chlorine compounds. An in-line mixer with a 60 second resident time is included to replace the static mixer. As a result, more electricity is needed to operate the system. In addition 
to the system, other instrumentation are needed: $\mathrm{pH}$ meter, $\mathrm{DO}$ meter, turbidity meter, jar testing equipment, sedimentation column, filter tower and drying oven. Table 4 lists the estimated costs for these items.

Table 3 List of Construction Materials

\begin{tabular}{|l|c|}
\hline Item & Cost \\
\hline 250 gallon equalization basin & $\$ 700$ \\
\hline Centrifugal Feed Pump 5 gpm & $\$ 200$ \\
\hline Flow meter & $\$ 160$ \\
\hline $\begin{array}{l}\text { In-line mixer (60 secs res. Time } \\
\text { at 4.5 gpm) }\end{array}$ & $\$ 800$ \\
\hline 2 dosing pumps with reservoirs & $\$ 600$ \\
\hline Flocculation tank & $\$ 650$ \\
\hline 3-variable speed gear motors & $\$ 900$ \\
\hline Polymer solutions (estimate) & $\$ 100$ \\
\hline Settling tank & $\$ 300$ \\
\hline Filter tank & $\$ 200$ \\
\hline Filter materials & $\$ 300$ \\
\hline Ozonator for Disinfection & $\$ 1500$ \\
\hline Structure Support Materials & $\$ 1000$ \\
\hline $\begin{array}{l}\text { Mixer Paddle Materials (worst } \\
\text { case) }\end{array}$ & $\$ 500$ \\
\hline Total Materials Cost & $\$ 7,910.00$ \\
\hline
\end{tabular}

Table 4 Additional Water Instrumentation Equipment

\begin{tabular}{|l|r|}
\hline Instrumentation & Cost (\$) \\
\hline $\mathrm{pH}$ meter & 400.00 \\
\hline Dissolved Oxygen Meter & 988.00 \\
\hline Turbidity Meter & 1000.00 \\
\hline Jar Testing Equipment & 2050.00 \\
\hline Sedimentation Column & 300.00 \\
\hline Filter Tower and Drying Oven & 1310.00 \\
\hline Total Lab Cost & $\$ 6,048.00$ \\
\hline
\end{tabular}

\section{Educational Value and Challenges}

This project was very labor intensive especially for two people. Having previously mentoring three other students in their senior projects, I began to question the value a project where the student does not build anything and only designs something on paper. My most valuable learning experiences in industry was when I actually designed and build something. As a result, I encouraged this student to do the same. The student agreed with my assessment when the project was over even though it really took too much time for two people. Many students have problems relating the abstract formulas to reality. Students who build something like thisgoing through the design equations and actually building with their hands what they put on paper is really the best education. It greatly improves their mechanical skills as well. Rarely do 
students participate in a real project. Arguably that is what co-op and internships are for-relate abstract concepts to real processes. In addition, the logistics of building and storing a rather large "lab" experiment can be taxing. The project was build in the evenings and on Saturdays. The initial trip to the Mississippi River was a failure due to the gear motors pulling away from the bottom of the tank and the pump failed. These problems were corrected and a second run produced adequate results. During this second run, the particles were not settling appropriately. It is believed that the static mixer did not provide adequate mixing and really should have been tested before the experiment. The positive experimental results were due to the three-layer filter removing the unwanted particles in the water.

Two other people greatly contributed to the project. Another civil engineering student name Jessica Brown had already finished her senior project and thought the project was very interesting. A retired electrician from Dupont volunteered to wire the gear motors and helped to transport the system to the river. It was the senior project for the engineering student and the adjunct professor initiated the project, and the student decided that she wanted to do it. The student believed that it was their best educational experience in college. Should someone else decide to create a similar system, it is advised to buy pre made tanks. Most likely there are better designs and group of six students participating as a group effort for a senior project would result in a potentially challenging and fulfilling project. Civil, electrical, computer programmer, microbiologist, and chemical engineers working as a group could build a computer monitored and feedback controlled system.

\section{Multi-disciplinary Project Potential}

Process optimization is the goal of any engineer running a system. Process optimization is performed via instrumentation and control strategies. This project could be greatly enhanced with the help of mechanical, electrical, and computer programming students. The process could be fitted with $\mathrm{pH}$ and turbidity meters and a feedback or feedforward control schemes could be devised to control dosing pumps, gear motors to alter the mixing speeds to produce the desired water quality. Considering the costs of laboratory experiments that can be purchased off the shelf that result in a limited learning experience, allowing the students to make their own system and model it mathematically would result in a great education experience whether they are chemical, mechanical, electrical, or civil engineers

\section{Acknowledgements}

The authors would like to thank Leonard Dunbar (an electrician) for wiring the gear motors and furnishing transportation to the Mississippi river. Jessica Brown volunteered her time to help in the construction process. The Dupont Corporation donated the acrylic sheeting to line the walls of the vessels. Bill Eicholtz of Nalco Water Inc in Knoxville, TN donated all coagulants to be tested. Memphis Light, Gas, and Water performed the analytical results. Dr. Robert Blanks then Chair of the CBU chemical engineering department paid for everything not donated to the project. 


\section{References:}

Cornwell, David A. and Mackenzie L. Davis. Introduction To EnvironmentalEngineering. 3 ed., McGraw-Hall: New York, 1998.

Levitt, Maureen, Personal Communication, Remediation Specialist for IT Corp Knoxville, TN, 2000.

Montgomery, James. Water Treatment Principles and Design.. John Wiley \& Sons: New York, 1985.

Reynolds, Tom D. and Paul Richards. Unit Operations and Processes in Environmental Engineering. $2^{\text {nd }}$ ed., Publishing Company: New York, 1996.

\section{Author's Biographies}

Paul Dunbar is an Assistant Professor of Chemical Engineering at the University of Kentucky Paducah Extension Campus (2000). He was an adjunct professor at Christian Brothers University at the time of this project. His research interests include bioremediation, structured biochemical modeling, and the electrochemical properties of uranium.

Lori Morris is a Civil Engineer (EIT) employed at Ensafe Inc. in Memphis, TN. She currently works on various waste water treatment projects. At the time of this waster treatment project was a senior in Civil and Environmental Engineering at Christian Brothers University. She was recognized as the outstanding civil and environmental engineering student in 2000.

L. Yu Lin is a Professor of Civil and Environmental Engineering at Christian Brothers University. He received his Ph.D. from Central Florida University in 1984. His major research interests are Fate and Transport of Pollutants, Pollutant Treatment, Computer Modeling in Environmental Engineering. 